\title{
The Agony of Puerperal Psychosis on Women in Childbirth: Implications for Counselling and Health Education
}

\author{
Ime N. George ${ }^{1, *}$, Felicia S. Ekpu ${ }^{2}$, Eme E. Imah ${ }^{1}$ \\ ${ }^{1}$ Department of Educational Foundations, Guidance and Counselling, University of Uyo, Uyo, Nigeria \\ ${ }^{2}$ Department of Physical and Health Education, University of Uyo, Uyo Nigeria \\ *Corresponding Author: nsisong99@yahoo.com
}

Copyright (C) 2013 Horizon Research Publishing All rights reserved.

\begin{abstract}
Puerperal psychosis is a rare but serious mental stress disorder triggered within a few months after childbirth. It is considered one of the most dangerous forms of post- partum stress disorders, which could lead to a tragic outcome if not detected and treated quickly. This paper examines the causes of the health condition as being; previous history of bipolar disease, hormonal changes, chromosomal problems, severe economic difficulties, lack of social support, poor self-image, and strained relationship with spouse among others. The signs and symptoms explored include anxiety, restlessness, sadness, depression and hallucination. Consequently, the necessity for counselling and health education need not be overemphasized as the pregnant women should be counselled right from prenatal period for the need to be emotionally and psychologically adjusted during childbirth. There is also great need for strong family involvement and support, psychiatrist services should be sought and judicious administration of prescribed drugs to clients to avoid relapse of the health condition, above all health education at all stages to the child-bearing families.
\end{abstract}

Keywords Women, Childbirth, Puerperal psychosis, Adjustment Counselling, Health Education

\section{Introduction}

Child birth is a universally celebrated event, an occasion for dancing, fireworks, flowers or gifts. Yet, for some women each day, childbirth is experienced not as joyful event as it should be but, as a private hell and agony that may even end in death. Practically, in every society, celebration of life is the dominant theme, while the grimmer side of child bearing is often shrouded in silence, known only to those who attend and suffer it and those who attended them. For anyone who has been through the experience or seen someone else go through it, there is no doubt that child birth is a life changing event.

Unfortunately, as wonderful and joyful experience as it is for many, it can also be a difficult period bringing with it new problems as well as the potential for suffering. Being a new mother is supposed to be the best feeling there is. But it's not the case for everyone. It can be lonely, upsetting, and terrifying. The sleepless nights never seem to end. The screaming can go straight through and often the only feeling left is one of numbness. In extreme cases, the mother or baby or both may die; these deaths are only the tip of the iceberg. Many health problems are laid down in the critical hours of childbirth both for mothers and child. Many more continue to unfold in the days and weeks after birth. Pregnancy and childbirth is often a journey into the unknown. Ball [1] described the transition to motherhood as a life crisis, an emotional watershed, a period of heightened sensitivity when the woman will be extremely vulnerable. Motherhood itself brings out paradoxes that permeate life, Ball asserted.

Childbirth is a process involving pregnancy, labour and puerperium. In all these stages many women find coping with the physiological adaptation first to pregnancy, the plethora of antenatal screening tests, issues around choice, control and communication emotionally draining. Labour also poses its own challenges in relation to the birth companion, pain management, intervention, technology and the actual process of birth.

During puerperium, parents may find coping with the demands of a new baby, viz, infant feeding, the financial constraints and adjusting to changes in their roles and relationship - a practically testing time emotionally. Johnstone [2] viewed post-partum experience as one of the peaks and valleys, as in any transition, noting that there will be losses as well as gains. He hails puerperium as the "fourth trimester" and by definition as a period from birth to 6-8 weeks post-partum, when the woman is readjusting physiologically and psychologically to motherhood. Her emotional response may be just as intense and powerful for experienced, as well as for new mothers.

The major psychological changes therefore being 
emotional, throwing the woman's mood as a barometer, reflecting the baby's needs for feeding, sleeping and crying patterns. Ball [1], Barcley and LIoyd [3] described that; normal emotional changes in the puerperium are therefore eclectic and complex. In the same light, Cohen [4] was of the opinion that, these eclectic and complex emotional changes experienced by $50-80 \%$ women depending on parity are erroneously categorized as a form of mental illness. Perhaps, because previous researches considered it an antecedent post-natal depression [e.g. 5]. These authors opined that the mean onset typical occurs within 3-4 days post-partum, with labile emotions, (e.g. tearfulness, euphoria, disturbed sleep, anxiety and laughter).

On the other hand, Cohen [4] observed that while 50-80\% of women experience these emotional changes during puerperium which only last for about 3-4 days, approximately, 2-3 women per 1000 births are affected with a more serious mental condition known as puerperal psychosis. This disease condition has been known since antiquity, consistent evidence in medical research studies over 100 years show that it affects $2-3$ women per every 1000 births leading to psychiatric admission. Although the least common of the post-partum syndromes, puerperal psychosis is regarded as the most severe and dramatic of the psychiatric disturbances to occur in the post-partum period [6]. Studies by Jones and Craddock [7] indicated that $85 \%$ of women develop some form of post-partum mental illness and up to half of nulliparous women with manic depression develop an episode of severe psychiatric disturbance with a few days after giving birth.

The relative risk for puerperal psychotic illness has been found to be $29 \%$ in subsequent pregnancies especially after an effective episode in the first 30 days after delivery [8]. Other researchers like Harris and Newcombe [9] observed that, post-partum psychosis is not a unitary clinical entity, and psychiatrists also disagree on the time interval after birth varying from six weeks to one year. Epidemiological studies conducted in USA and Great Britain using research diagnostic criteria indicated low incidence rate (about $1-2$ per 1000 births).

Oates [10] noted that in many developing countries, only few studies have been carried out on this problem and the incidence is not known. In Nigeria, Ifabumiyi and Akindele [11] in their study of mothers of corresponding age with puerperal psychosis in Northern Nigeria, found $66 \%$ to be primiparous. Ifabumiyi and Akindele also observed that young primigravida are most probably ill-prepared psychologically to cope with motherhood together with stress of marriage system. This fact is therefore indicative of the agony that some women pass through during childbirth. This paper therefore sought to unfold what puerperal psychosis is, the causes and symptoms, and what can possibly be done as an intervention to prevent/reduce the prevalence of this malady in motherhood.

\section{Literature Review}

Puerperal psychosis is rare but acute mental illness which has a sudden onset within the first few weeks (usually within the first 10 days) following childbirth, and most prevalent among new mothers. It can develop suddenly, within a few hours [12-14] Post-partum psychosis occurs 1 - 2 in every 1000 births and over $80 \%$ of the cases are effective in type and the onset is usually within the first two weeks following delivery $[13,15-16]$. In addition to the classical features of an effective psychosis, disorientation and confusion are often noted. Severally depressed patients may have delusional ideas that the child is deformed, evil or otherwise affected in some way and such false ideas may lead to either attempts to kill the child or suicide, hence, the response to speedy treatment is generally good.

Puerperal psychosis is totally different from postnatal depression (though, women who experience puerperal psychosis may feel depressed) [17]. Women with previous history of bipolar disorder or schizoaffective disorder in the past may also experience a relapse following childbirth. Researchers explain that an episode of puerperal psychosis follows between 25 and 50 per cent of births to women who have bipolar or schizoaffective disorder. Moreover, women who experienced it after the birth of their first child will almost inevitably experience it again, following the birth of a second child, and after subsequent births $[8,17]$.

It is also pertinent to note that if there is a family history of puerperal psychosis, the risk of developing it is higher; research has shown that, women are more likely to experience puerperal psychosis if their mothers or other close relatives did. This applies equally to women who have no previous personal experience of mental illness. There is no greater risk of developing puerperal psychosis if a woman's mother or other close relative has experienced postnatal depression or other postnatal mental health problems [17].

\subsection{Causes of Puerperal Psychosis}

Puerperal psychosis appears to be much less related to stress factors, according to Cooper and Murray [5], and more related to biochemical changes. However, the evidence about its biophysical origins, though plausible, remains equivocal $[9,18]$ and most mothers with puerperal psychosis will be experiencing mental illness for the first time. Oates [10] submitted that there is a strong association between family history of a manic depressive disorder (mother or father) and puerperal psychosis suggests a genetic link. Risk factors like first pregnancy, poor relationship with partner, ambivalence about the pregnancy and emotional personality traits have been suggested as factors that aggravate puerperal psychosis. Generally, however, women with a history of mental illness that required hospitalisation have a higher chance of having puerperal psychosis [19]

Marcé, cited in Oates [10] asserted that puerperal psychosis is also linked to menstruation, and especially menstrual psychosis, as an important clue to the cause. Similarly, Brokingston [20] opined that molecular genetic 
studies suggest that there is a specific heritable factor and evidence to chromosome linkage even though the chromosome is not yet named. Other predisposing causes include, poor self-concept, severe economic difficulties, lack of social support, anxiety and depression.

\subsection{Onset of Puerperal Psychosis}

Many researchers such as Oates, [10], Cohen [5], Jones, Hamshere, Nagle, Benmiddle, Green, Heron, Sequardo and Lambert [21], and Williams, [12] mentioned the following signs and symptoms;

- Often the first signs of puerperal psychosis are related to sleep. The woman may find it very hard to sleep from the time her baby is born and she has almost no sleep at all the first few nights or even longer.

- While some excitement and sleep difficulty on the first night after childbirth are common, and an infant can keep new mothers awake for many weeks, most women after the first night want to sleep and usually can do so if the baby allows her.

- For a woman developing puerperal psychosis, other things begin to happen. The symptoms are quite variable. She can be full of energy, very restless and irritable, and believes that she has special powers or strengths that makes her unbeatable in any way.

- Some women become very obsessed with their new born baby but many are so busy doing things like telephoning their friends in the middle of the night or making plans to save the world some way that they almost ignore their baby.

- While a woman may want to do the right thing for her baby, she is often lacking in organization and cannot sit still long enough to feed her baby properly.

- Some women feel paranoid as though people are trying to harm them or their baby and unfortunately these feelings may be directed towards family members, who are worried by the woman's behaviour and trying to assist her to get help.

\subsection{Phases of Puerperal Psychosis}

- By about 4 to 14 days after the baby is born, it is becoming clear to everyone that something is seriously wrong.

- The woman may be very irritable and begins to believe things are clearly not true - these are called delusions - fixed false beliefs that may be very harmless, and can sometimes lead to the woman harming herself, her infant or may be others.

- This may also be because she is hearing voices (auditory hallucinations) or seeing things (visual hallucinations), which aren't there (this is less common).

- She will talk quickly, often not finishing sentences or ideas, can be quite elated or confused and her moods may vary within a very short space of time.
- If she is stopped doing what she wants, she may become very abusive and aggressive in a way, which is quite out of character.

- Frequently, women will deny that there is anything wrong and refuse to stop what they were doing or think about the fact that other people find their behaviour strange or out of character.

- During this phase, a new mother may seem quite confused and forgetful. This of course will make her very disorganised just at a time when she is trying to learn new skills in caring for her baby and this can very quickly become a very upsetting situation.

\section{Depressed Phase}

After days or sometimes several weeks, depending on factors such as treatment, the panic phase may stop as suddenly as it had started and the woman may become extremely depressed.

- Her mood becomes very depressed, she is very lacking in energy, does not want to sleep or eat, may begin to think of killing herself, (and/or sometimes her baby), and her concentration is very poor.

- She may just sit around, it is hard to have a conversation with her, she is very tearful and hates herself. She feels hopeless, helpless and worthless, especially as a mother. There is very little energy to do everything and she may stop caring for herself and the baby.

\subsection{General Care of the Patient}

Women often need assistance with looking after their babies safely, and keeping themselves safe and cared for as well.

- Sleep is a real problem for women suffering from puerperal psychosis and is an essential part of getting well so she should be reassured and encouraged to sleep as much as she can.

- Oftentimes clients appear to deteriorate when they are admitted to hospital and this happens for several reasons. It may be that the lack of sleep is beginning to have more effects, or that the woman is irritated by the restrictions which being in hospital may impose. It can also be the natural progression of the illness. As clients often cannot understand that they are unwell, anger can be quite obvious.

\subsection{Family Role in the Care of the Patient}

Researchers in the field of medicine like Gregoire [18], Harris and Newcombe [9] and Williams [12] were of the opinion that family involvement in the care of puerperal psychotic patient is very important, thus;

- The partner and other immediate family members should be informed to be available for support.

This illness although relatively rare as mentioned, often occurs for the first time after birth of a first child, 
which makes things very hard indeed for the new family.

- The new father may find his partner suddenly unwell and not able to come home and he may find separation from his partner and child very difficult. He may also need to get support from family, friends or professionals.

- Getting more information about the condition can be very helpful in coming to terms with what is going on but it is clear that it is a difficult time.

\subsection{Effects on Baby and Family}

When a woman is really unwell especially in this magnitude, it poses a serious problem caring for the baby and the entire family, she may be at risk of deliberately harming her baby because of some unusual belief she has related to her illness. In the early days of her being unwell therefore, it is important for one to keep very close eye on her so that harm cannot happen to her baby. A woman may also neglect her infant because she is so excited and restless, she may intend to do the right things for her baby but cannot do so because she isn't organised enough and lacks concentration. Staff and relations therefore will need to be very involved in helping care for herself and the needs of her baby.

Furthermore, when a woman is depressed, she may find it difficult to have enough energy to look after her baby properly and may need some help at this stage too. Sometimes the medication(s) she is taking also interfere with her care of her baby and there are concerns about breastfeeding while on medication. The woman, her family and the doctor, must discuss the risk/benefits of medication with breastfeeding so that everyone has enough information and understand the best choices for each situation [12]. William also explained that in the long term, when these safety factors are adequately addressed, follow-up studies have shown that the babies grow up without any major consequences of their mothers' illness. Other family members, e.g. partners, parents and other children in the family may also find the going tough in the early times of the illness when a woman is clearly very unwell and everyone is coming to terms with the illness.

\subsection{Medical Treatment}

From various researchers, and numerous symptoms enumerated, it is clear that puerperal psychosis is a clear illness and requires urgent specialist treatment. For most women, admission in hospitals for prompt and specialist management is the best pathway. Their treatment usually consist of antipsychotic medication, in other words, tablets or sometimes injections which calm her down, slow her thinking and behaviour, and help her get back on touch with reality [12, 17, 22-23].

She will often also need mood stabilizers in order to stabilize her mood and if she is depressed which is part of the illness-antidepressants, all, subject to specialist's prescription and management. Further treatment may include electroconvulsive therapy, which is often recommended in very severe cases.

Researches have proved that most women with this condition need to be treated in hospital, and are likely to be in hospital for at least $2-3$ weeks. Moreover, when she is discharged home, the woman still needs to be taking medication often for $6-12$ months and this requires discussion with her family before discharge. Generally, a woman will need to continue to see the psychiatric doctor and perhaps a mental health nurse after discharge who will monitor her medication and help to determine the length of time that she needs to stay on it. She may also want support with her baby and this may involve child and youth health or other agencies. Generally, although puerperal psychosis is a rare condition, for those women who have had in the past, the chances of the illness recurring after another delivery have been estimated at between one in two or one in three. [17, 22-24]

\subsection{Prognosis}

Research by Cooper and Murray [5] suggested that, not only does post-partum psychopathology respond well to psychological interventions but they generally have a good prognosis. Although there is a risk of mental illness with subsequent pregnancies, the good news is that women do recover to carry on with their lives. Women will recover from puerperal psychosis, but those who have a personal history of psychosis, whether or not related to childbirth, have $1: 2$ and 1:3 risk of having the disorder after the birth of any other children. Furthermore, the risk of recurrence of a severe mental illness is at its greatest in the first 30 days post-partum. [8]. The risk is estimated to be highest if the woman has another child within 2 years of recovery.

\section{Implications to Counselling and Health Education}

Childbirth is a process involving pregnancy, labour and puerperium. During these stages a woman undergoes many physiological and psychological changes that are sometimes traumatic. This therefore implies that counselling of all pregnant women on these changes in order to help them adjust and adapt psychologically and physiologically through these stages is necessary. Pregnant women with previous history of bipolar disorder, puerperal psychosis in childbirth be counselled separately on the need to continue their prophylaxis throughout pregnancy and puerperium to avoid peripartum relapse.

Counsellors should listen to their clients to talk them out of internal and external depression triggers, and signs of severe depressive episodes that can result in psychosis. Client's spouse/partner and family should be educated on the symptoms, ways of coping and most vitally helping the client in sorting through healthy behaviours and those that enable 
psychotic behaviours. Clinicians, require counsel to be proactive in identifying women at risk and providing appropriate counselling and referral where applicable. The condition calls for effective health education to all women of child bearing age on how to rest, relax and exercise adequately before and during pregnancy. It also calls for commitment and proper dissemination of health information by the health educators

\section{Conclusion}

The mental health and general wellness of a mother during puerperium is vitally important to the new born baby, spouse/partner, the family and the society at large. Puerperal psychosis is a serious health problem that requires being proactive in screening and identification of women at risk to ensure adequate care and referral where necessary. The role of preventive work through education, information provision and development of self-help strategies are of great importance in reducing the triggers of this health condition. There is also need for strong family involvement and quick referral for appropriate medical attention at the very onset.

\section{REFERENCES}

[1] Ball, J. A. (1994). Reactions to motherhood; The role of postnatal care, (2nd ed.) Books for Midwives Press; Hale, Cheschire.

[2] Johnstone, M. (1994). The emotional effects of childbirths: a distance learning course for midwives, health visitors and others who are for women around the time of birth. London; Marc Society

[3] Barclay, I., \& LIoyd, B. (1996). The misery of motherhood: Alternative approaches to distress. Midwifery, 12 (3): $136-138$

[4] Cohen, L. S. (1995). Postpartum psychiatric disorders. Acta Psychiatric Scand 91: 57-67.

[5] Cooper, J. P., \& Murray, L. (1997). Effects of postnatal depression. British Journal of Midwifery 3 (2): 99 - 104.

[6] Kendell, R. E., Chalmers, L., \& Platz, C. (1987). The epidemiology of puerperalpsychosis.British Journal of Psychiatry 150:662-673.

[7] Jones, I., \& Craddock, N. (2001). Familiarityof the puerperal trigger in bipolar disorder: result of a family study. American Journal of Psychiatry 158:913 - 917.

[8] Lewis, G., \& Drife, J. (Eds.) (2001). Why mothers die (19971999): The fifth report of the confidential enquiries into material deaths in the United Kingdom. RCOG, London.
[9] Harris, B. L., \& Newcombe, R. G. (1994). Maternity Blues and Major endocrinechanges: Cardiff puerperal mood and hormone study 2. British Medical Journal 308:949 - 954.

[10] Oates, M. R. (2000). Psychiatric disorders in pregnancy and puerperium. In Campbell S. L. (Ed.) Obstetrics by ten teachers (17thed,) Arnold; London

[11] Ifabumuyi, O. I., \& Akindele, M. O. (1980). Postpartum mental illness in Northern Nigeria. Acta Psychiatry Scand $83: 64-65$.

[12] Williams, A. S. (2004). Puerperal psychosis information, Sue Ellershaw; Australlia.

[13] RCP. (2012). Postnatal depression. Royal College of Psychiatrists. www.rcpsych.ac.uk [Accessed March 2013]

[14] SIGN. (2012). Management of perinatal mood disorders: a national clinical guideline. Scottish Intercollegiate Guidelines Network. www.sign.ac.uk [pdf file, accessed March 2013]

[15] MIND. 2010. Understanding Postnatal Depression. National Association for Mental Health. www.mind.org.uk

[16] NHS Choices. 2012. Postnatal Depression. NHS Choices, Health A-Z. www.nhs.uk

[17] Royal College of Psychiatrists (2013) Postpartum Psychosis: Severe mental illness after childbirth. Retrieved: http://www.rcpsych.ac.uk/healthadvice/problemsdisorders/p ostpartumpsychosis.aspx Date 27/09/13

[18] Gregorie, A. (1995). Hormones and post natal depression. British Journal of Midwifery. 2: 99-104

[19] Harlow BL, Vitonis AF, Sparen P, et al. (2007). Incidence of hospitalization for postpartum psychotic and bipolar episodes in women with and without prior prepregnancy or prenatal psychiatric hospitalizations. Archives of General Psychiatry. 64: 42-48.

[20] Brockington, I. F. (2008). Menstrual psychosis and the catamenial process.s Brendenbury; Eyry press

[21] Jones, I., Hamshere, M., Nagle, J. M., Benmiddle, F., Green, E., Heron, J., Sequardo, R., \& Lambert, D. (2007). Bipolar affective puerperal psychosis: genome - with significant evidence for linkage to chromosome. Psychiatry 164:1-6.

[22] Doucet S, Jones I, Letourneau N et al. (2011). Interventions for the prevention and treatment of postpartum psychosis: a systematic review. Archives of Women's Mental Health. 14(2): 89-98.

[23] Jones I and Smith S (2009) Puerperal Psychosis: Identifying and caring for women at risk. Advances in Psychiatric Treatment. 15: 411-418.

[24] NICE Clinical Guideline 45. (2012). Antenatal and postnatal mental health: clinical management and service guidance. National Institute for Health and Clinical Excellence: London. 